\section{Treating Patients with Antipsychotics: an Individualized Management REVIEW}

\section{Abstract}

Introduction: Subjective well-being, quality of life, cognition and psychosocial performance, including employment, have become endpoints of interest and goals for patients, families, clinicians and researchers. In this line, it is important to clarify the adverse effects caused by antipsychotics in order to innovate and complement treatment of patients with an individualize approach according to the patient's needs and predispositions.

Objectives: Discuss new treatment's way for patients using antipsychotics, elucidating the pros and cons of their use.

Results: Atypical antipsychotics cause weight gain and lead to a higher risk of diabetes and other metabolic sequelae than their typical counterparts. Besides, second-generation(atypical) has also shown adverse effects like: akathisia, sedation, abnormal metabolic laboratory results, and weight gain. On the other hand, talking about the first-gentration (typical) antipsychotics, their clinical effectiveness is challenged by increased acute and chronic extrapyramidal side effects and related symptoms of dysphoria, compared to second-generation (atypical) antipsychotics. In addition, available evidence indicates that antipsychotic medications increase the risk of cerebrovascular adverse events (CVAEs) and death when used to treat elderly patients with Behavioral and Psychological Symptoms of Dementia (BPSD). Besides, some studies show that patient populations that are prescribed antipsychotic agents have a higher cardiovascular mortality rate than the general population. Considering that, we can see that each psychotic patient will need an individualized treatment according to their physical, social and psychological limitations and needs, leading us to realize the significance of this paper since it emphasizes the holistic management of this kind of patient.
Laís Chaves Maia1, Camilla Barros Meireles ${ }^{1}$, Victoria Aline Linhares Miná1, Fábia Maria de Santana², Danielly Michele Gondim Matias ${ }^{2}$,

Aurélio Dias Santos ${ }^{3}$, Alberto Olavo Advíncula Reis ${ }^{4}$, Modesto Leite Rolim Neto ${ }^{1,3}$

1 Faculty of Medicine. Federal University of Cariri, UFCA, Barbalha, Ceará, Brazil.

2 Postgraduate Program in Health Science, Faculty of Medicine - FMABC, Santo André, SP, Brazil.

3 Physiotherapy Course, Faculty Leao Sampaio, Juazeiro do Norte, Ceará, Brazil.

4 Faculty of Public Health. University of São Paulo, USP, São Paulo, São Paulo, Brazil.

Contact information:

Modesto Leite Rolim Neto.

”modestorolim@yahoo.com.br 
Conclusion: With the aim of known safety concerns and uncertainty over long-term risks and benefits, it is clear the need to reevaluate clinical practice standard and strengthen efforts to educate especially primary care physicians, concerning the known safety and efficacy of antipsychotic medications to give the patients a treatment that is based on their quality of life.

\section{Keywords}

Antipsychotics; Quality of life; Manegement.

\section{Introduction}

The medical practitioners are divided largely into two polar camps: the analytical and psychological vs. the organic and directive. The first group developed an ideology that rejects the use of organic treatments and directive methods as usually ineffective, symptomatic at best, and destructive of the growth potential of the patient by fostering pathological dependence (KANE et al., 2010).

Antipsychotics are widely used in treating psychosis and other psychiatric conditions (PAULOSE-RAM et al., 2007; ChIEN et al., 2007). Their primary indication remains schizophrenia and schizophrenia-related disorders, but most antipsychotic drugs are now used on-label to treat a broad range of symptoms and disorders, including bipolar mania and depression, unipolar depression that is unresponsive to standard antidepressant treatment, Tourette's disorder and irritability associated with autistic disorder (HERT et al., 2012).

However, the opinion of analytical and psychological is reinforced by the obvious ineffectiveness of most organic therapies, complicated by the addictive potential and social incapacitation often produced by antipsychotic medications (KANE et al., 2010).

These medications are associated with risk of cerebrovascular adverse events (CVAEs) and death when used to treat elderly patients with dementia (MitTAl et al., 2011) and can induce cardiovascular and metabolic abnormalities (obesity, hyperglycemia, dyslipidemia and the metabolic syndrome) that are associated with an increased risk of type
2 diabetes mellitus and cardiovascular disease (HERT et al., 2012).

Thereby, it is important to clarify the adverse effects caused by antipsychotics in order to innovate and complement treatment of patients with unified treatments that does not follow the universal protocol and individualize treatment according to the needs and predispositions of the patient and should include components like: 1) psychoeducation/boosting motivation increasing self-knowledge and becoming a partner in therapy; 2) cognitive reappraisal (learning to think accurately about one's own thinking); 3) preventing emotional avoidance (accepting emotional experience and increasing emotional literacy); and 4) changing behavioral habits in the context of exposure treatment (Schramm et al., 2011; BARLow et al., 2011).

\section{Results/Discussion}

In order to make clear why it isimportant to haveother forms of treatment, like transdiagnostic approach, we will elucidate the scientificdivergencesthat involvemost common medicationsused to treatpsychiatricdisorders in order emphasize the besttreatmentto promotes patient'squality of life.

Atypical antipsychotic medications are approved for marketing and labeling by the US Food and Drug Administration (FDA) for treating schizophrenia, bipolar disorder, and depression under drug-specific circumstances (MAHER et al., 2011). In this line, due to their importance, it is relevant to discuss about their approaches. 
Over the last two-decades, first generation or "typical" agents introduced in the late $1950 \mathrm{~s}$ and 1960 s have largely been replaced by a second generation of "atypical" antipsychotics (AleXANDER, et al. 2011). Apparently this change is based on the facts that It has been shown that conventional antipsychotics are equally or even more harmful compared with atypical antipsychotics (GILL et al., 2005; HerRmann et al., 2004; LAYTON et al., 2005; Wang, et al., 2005; Kales et al., 2007; KLeIJer et al., 2009).

Moreover, the clinical effectiveness of first-generation antipsychotics, a measure of objective and subjective outcomes encompassing symptom-based and functional effects, is challenged by increased acute (FISCHER-BARNICOL et al., 2008) and chronic (Correll et al., 2004) extrapyramidal side effects and related symptoms of dysphoria, compared to second-generation (atypical) antipsychotics (SGAs) (KAnE et al., 2010). However, serious and distinct adverse effects of atypicals have emerged (ALEXANDER, et al. 2011).

The most commonly prescribed atypical antipsychotic medications are quetiapine, risperidone, aripiprazole, and olanzapine (AleXANDer et al., 2010). Other atypical antipsychotic medications include asenapine, clozapine, iloperidone, paliperidone, and ziprasidone (MAHER et al., 2011).

Atypical antipsychotics cause weight gain and lead to a higher risk of diabetes and other metabolic sequelae than their typical counterparts (ATKIns et al., 2004; MAHER et al., 2011). Besides, it is important to balance thepositive and negative aspects of each drug applied for a specific disorder, since, for example, a study on anxiety in patients with bipolar disorder found that risperidone was no more effective than placebo (SheeHAn et al., 2009; Maher et al., 2011). Additionally, for major depressive disorder, adjunctive aripiprazole was frequently associated with akathisia and also linked to a statistically significant elevation in the occurrence of sedation and significant weight gain.

Overall, SpIeLmANs, et al. 2013, found that treatment was linked to several adverse events, including akathisia (aripiprazole), sedation (quetiapine, olanzapine/fluoxetine combination (OFC), and aripiprazole), abnormal metabolic laboratory results (quetiapine and OFC), and weight gain (all four drugs, especially OFC). (SPIELMANs et al., 2013)

So, it is relevant to attempt to thoroughly understand the risk-benefit profiles of these adjunctive treatments for major depressive disorder taking into account the lack of benefit with regards to quality of life or functional impairment, and the abundant evidence of potential treatment-related harm (SPIELMANs et al., 2013).

On the other hand, talking about the typical ones, studies concluded that commonly prescribed doses of haloperidol, olanzapine, and risperidone, but not quetiapine, were associated with a shortterm increase in mortality. (MıtTAL et al., 2011) The findings of NASRALLAH et al., 2004, suggested that the mortality in elderly patients receiving haloperidol is significantly higher than in those receiving the atypical antipsychotics risperidone or olanzapine.

Even though, the use of typical agents has declined, but continues predominantly for schizophrenia. In contrast, atypical agent use has dramatically increased, both substituting for typical agents and expanding into new indications, such as bipolar disorder and depression. (AleXANDER, et al. 2011) (Figure 1)

Figure 1: Adverse effects of antipsychotic.

\section{FIRST-GENERATION ANTIPSYCHOTICS}

$\longleftrightarrow$ Extrapyramidal side effects + symptoms of dysphoria

\section{$D$ SECOND-GENERATION ANTIPSYCHOTICS:}

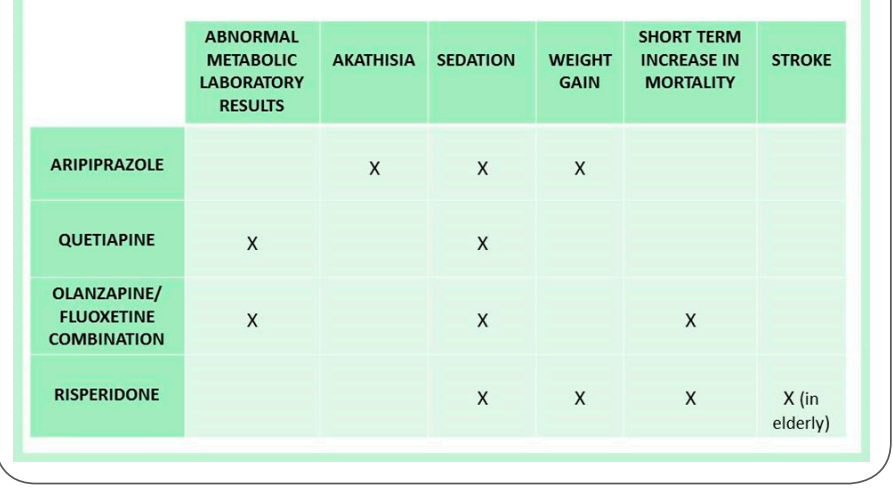




\section{Cerebrovascular Risks}

Behavioral and Psychological Symptoms of Dementia (BPSD) have been defined as a heterogeneous range of psychological reactions, psychiatric symptoms, and behaviors, which may be disruptive, unsafe, and impair the care of the patient in a given environment (Bharucha et al., 2002; MitTAL 2011). Increasingly, antipsychotic medications are being used to treat these behaviors (Alexopoulos et al., 2004; Schneider et al., 1990). However, there are emerging concerns about the cerebrovascular-related adverse effects of antipsychotic use (Wooltorton 2002; Mittal 2011; Wu et al., 2013). Available evidence indicates that antipsychotic medications increase the risk of CVAEs and death when used to treat elderly patients with BPSD. The risk is higher when used in patients with vascular dementia and above the recommended doses for these medications. The risk of CVAEs appears to remains high for about 20 months and the risk of death is elevated in the first 30 days and possibly to 2 years (MitTal et al., 2011).

Besides, according to KLEIJER et al., when patients use antipsychotics for more than 3 months, the increased risk returns to baseline levels. This can be explained as only those patients who tolerated their first exposure were able to receive more prescriptions. These patients apparently are less susceptible for the adverse cerebrovascular effects of antipsychotics. The study indicates to that conventional antipsychotics are more harmful than atypical antipsychotics. Potential mechanisms proposed to explain this association between antipsychotics and cerebrovascular events include thromboembolic effects, altered platelet function, cardiovascular effects (orthostatic hypotension, arrhythmias) and the atherosclerotic effects of deregulation of glucose and lipid metabolism (KLEIJER et al., 2009).

Judicious use of these medications with careful assessment of the risk/benefit ratio and close monitoring of the risk factors will reduce side-effects like CVAEs and death thereby prevent undue su- ffering to patients and their families (MitTal et al., 2011).

\section{Cardiovascular and Metabolic Risk}

Mechanisms underlying antipsychotic cardiometabolic adverse effects are incompletely understood. This hampers the identification of high-risk patients, low-risk antipsychotics and preventive/ ameliorative treatments. In addition, some studies show that patient populations that are prescribed antipsychotic agents have a higher cardiovascular mortality rate than the general population (CORRELL et al., 2011). Although all antipsychotic drugs can induce cardiovascular and metabolic dysfunction (especially in drug-naive, first-episode and pediatric populations), olanzapine and clozapine are most likely to cause such adverse effects. Besides, an unfavourable risk profile for myocardial infarction (MI) is associated with various lifestyle factors and co-morbidities that are more prevalent among patients with severe mental illness (BraUer et al., 2011).

These adverse effects are especially prominent in vulnerable populations, such as patients with a first episode of schizophrenia, those who have not previously taken antipsychotic agents (drug-naive), children and adolescents (HERT et al., 2011; MAAYAN et al., 2010; Correll et al., 2011). Nevertheless, patients receiving antipsychotic treatment, including these especially vulnerable groups, are often insufficiently assessed for cardiovascular and metabolic risk factors (Morrato et al., 2010; MorRato et al., 2010; Mitchell et al., 2012).

Patients with severe mental disorders are at even higher risk than the general population for obesity, for example (FleischHacker et al., 2008; HeRT et al., 2009). In addition to medical consequences, obesity in the mentally ill can cause treatment non adherence and decreased quality of life (MAAYAN et al., 2010).

In general terms, antipsychotic-related weight gain and obesity result from a medication-induced or - 
aggravated imbalance between energy intake (type, amount and frequency of ingested calories) and energy expenditure (type, amount and frequency of activity/exercise). Several moderators and mediators for weight gain during antipsychotic treatment that influence how much weight is gained have been reported, including patient factors (age, BMI, gender), familial factors (family history of obesity, parental BMI), illness-related factors (treatment naÏve, extent of symptom reduction, lack of prior antipsychotic treatment) and treatment variables (duration, dose and drug type) resulting in high inter-individual variability in weight gain (MAAYAN et al., 2010; CocCuRELLo et al., 2010).

Despite an increasing awareness of the clinical significance of antipsychotic-induced weight gain (Correll et al., 2009; Heart et al., 2009; MaAyan et al., 2010; MaAyans et al., 2010; PARsons et al., 2009), recent data suggest that the magnitude of this side effect has been constantly underestimated by studies in chronically treated adult populations since drug-naïve patients gain significantly more weight than patients exposed to antipsychotics in the past (Correll et al., 2009). For example, drugnaïve pediatric patients were at far greater risk for risperidone-induced weight gain than pediatric patients as well as adult patients with substantial prior antipsychotic exposure (CoRRell et al., 2009).

\section{Metabolic Syndrome}

The major components of the metabolic syndrome are generally agreed to include central obesity, hypertension, dyslipidemia, and glucose intolerance or insulin resistance. In general, the risk of developing the metabolic syndrome is greatest with clozapine, olanzapine and chlorpromazine. However, these associations can differ substantially in naturalistic cohorts of patients (Kessing et al., 2010), probably owing to confounding by indication (meaning that low-risk agents are mostly prescribed to patients at high risk of developing the metabolic syndrome) (HERT et al., 2012).
Olanzapine and clozapine are associated with the highest risk of dyslipidemia, whereas risperidone and quetiapine confer an intermediate risk, and aripiprazole and ziprasidone confer a low risk of this metabolic abnormality. The dyslipidemic adverse effects of clozapine, olanzapine and quetiapine manifest as abnormal elevations in levels of serum triglycerides and as an increase in total, LDL and non-HDL cholesterol levels (SIMON et al., 2009).

Another study conducted in antipsychotic-drugnaive pediatric patients showed a dose-dependent effect of olanzapine on serum lipid profiles and blood glucose levels, and a dose-dependent effect of risperidone on weight gain, as well as serum lipid pro-files (Correll et al., 2009). Abnormalities in glucose and lipid metabolism often occur via increased abdominal adiposity; however, antipsychotic drugs associated with pronounced metabolic adverse effects can also have a direct molecular effect (HERT et al., 2012).

The biological and behavioral risk factors for type 2 diabetes mellitus are well identified. The most important factors are overweight and obesity, particularly central obesity (QIN et al., 2010) and physical inactivity (QIN et al., 2010; HARTEMINK et al., 2006; AlberTi et al., 2007). Additional behavioral risk factors include smoking and a poor-quality diet (for example, low in whole grains and fiber) (HERT et al., 2011).

\section{Unsatisfying health care}

The majority of patients receiving antipsychotic treatment in psychiatric hospitals or general healthcare clinics are not monitored for metabolic risk factors, even those that are simple to measure, such as obesity and high blood pressure. (Moratto et al., 2010; Moratto et al., 2010; Barnes et al., 2007; LAMBERT et al., 2009; HAsnaIn et al., 2010; HeRT et al., 2012).

Even after publication of FDA warnings and recommendations from the American Diabetes As- 
Vol. 8 No. 264 doi: $10.3823 / 1863$ sociation (ADA) and the American Psychiatric Association (APA), the frequency of baseline testing for blood glucose and serum lipid levels in patients receiving second-generation antipsychotic agents have changed very little (MORATTO et al., 2010; HAUPT et al., 2009; HeRT et al., 2012).

Moreover, the publication of monitoring guidelines, showed that although guidelines slightly increased monitoring, most patients do not receive adequate testing for cardiovascular and metabolic abnormalities-a prerequisite for timely treatment of these abnormalities (Mitchell et al., 2012).Likewise, most children, who initiated treatment with a second-generation antipsychotic drug, did not receive the recommended screening for blood glucose and serum lipids (HERT et al., 2012).

Poor quality medical care contributes greatly to excessive mortality in elderly people with mental disorders, second only to heart failure (WheELER et al., 2010) Another important barrier is that few patients with mental illness seek medical help, even when they have acute cardiovascular syndromes. (WHeEleR et al., 2010; HenNeKens et al., 2005).

\section{Conclusion}

These findings emphasize the importance of establishing and implementing a standardized monitoring system for all patients receiving antipsychotic drugs. Clearly, lifestyle-related factors that are easy to measure, such as weight, waist circumference and blood pressure, should be monitored at appropriate intervals in all patients treated with antipsychotic drugs.

Subjective well-being (NABER, et al., 2005; LAMBERT, et al., 2006), quality of life (YUNG, et al., 1996), cognition (Green, et al., 2008; Harvey, et al., 2006; KeEFE, et al., 2010) and psychosocial performance, including employment (LeHMAN, et al., 2002; EVANS, et al., 2004; McGurk, et al., 2010), have become endpoints of interest and goals for patients, families, clinicians and researchers (Kane et al., 2013).
Healthy diet, regular exercise and smoking cessation reduce patients' cardiovascular and metabolic risk; low-risk antipsychotic agents, adding weightlowering medications and/or treating significant cardiovascular and metabolic abnormalities might also help.

In addition, psychiatrists, physicians, nurses and other members of the multidisciplinary care team can educate and motivate people with severe mental illness to improve their lifestyle through effective behavioral interventions, including smoking cessation, dietary measures and regular exercise. However, if lifestyle interventions do not succeed, other medications, including statins, antihypertensive therapy or antidiabetic agents, might be indicated. Moreover, pharmacologic treatments (such as metformin or topiramate) can be added to reduce antipsychoticdrug-related weight gain. New antipsychotic drugs should be developed that are weight-neutral and that do not have metabolic adverse effects, or that can even reverse pre-existing cardiovascular and metabolic abnormalities in patients with mental illness who are at an increased risk of cardiovascular and cerebrovascular morbidity and mortality (HERT et al., 2012).

To move toward these important goals, it has become clear that the field needs to study and engage in the routine application of measurement based psychiatry, clinical and shared decision making, psychoeducation and adherence management, as well as in the integration of rational psychosocial treatment elements in the often too one-sided pharmacologic treatment planning (KANE et al., 2010; DIXON et al., 2009). Future studies designed to investigate the coronary side-effects of antipsychotic agents are recommended.

In light of known safety concerns and uncertainty over long-term risks and benefits, these trends may signal a need to reevaluate clinical practice patterns and strengthen efforts to educate physicians, especially primary care physicians, concerning the known safety and efficacy of antipsychotic medications. At 
the same time, a new generation of clinical trials is needed to evaluate the safety and efficacy of antipsychotic medications in conditions for which they are commonly prescribed but for which the evidence base remains underdeveloped (OLFSON et al., 2012).

Facing the exposed discussion we can realize that it is necessary a new approach to treatment with antipsychotics aiming to reduce side effects, and to achieve an individualized therapeutic that covers the physical, psychological, and social limitations of each patient, treating the patient as a whole and not just the disease. Side effects should be compared to the benefits and only then action should be taken. Before prescribing risperidone, one should not overlook the patient's age, especially if he or she is elderly; it is a simple assessment that can reduce mortality and improve the patient's quality of life. Assessing the social occupation of the patient before determining the doses of the drugs, taking into account the sedation promoted by them, should also be a constant concern. Non-drug treatments like the ones shown in Figure 2 should also be stimulated.

Figure 2: New approach for reduced adverse effects of treatment with antipsychotic medication. CVAE: cerebrovascular adverse events.

\section{ADVERSE EFFECTS $\boldsymbol{*}$ NEW APPROACH}

\begin{tabular}{|c|c|c|}
\hline CAVE & \multicolumn{1}{|c|}{$\begin{array}{c}\text { Low dosages in the first days of treatment; } \\
\text { Carefull assessment of the risck/benefit ratio; } \\
\text { Close monitoring of the risck factor. }\end{array}$} \\
\hline \begin{tabular}{|c|c|} 
METABOLIC \\
SYNDROME
\end{tabular} & $\begin{array}{c}\text { Monitored weight, waist } \\
\text { circunference and blood pressure } \\
\text { in appropriate intervals }\end{array}$ \\
\hline \begin{tabular}{|c|c|} 
CARDIOVASCULAR \\
RISKS
\end{tabular} & $\begin{array}{c}\text { Health care team can educate } \\
\text { and motivate }\end{array}$ \\
\hline adherence management & $\begin{array}{c}\text { Regular exercise, } \\
\text { smoking cessation }\end{array}$ \\
\hline
\end{tabular}

\section{Acknowledgments}

We would like to thank Scientific Writing Lab, Medicine School - Federal University of Cariri - UFCA for the support.

\section{Conflict of Interest}

The authors have declared no conflicts of interest.

\section{Role of Funding Source}

None.

\section{References}

- Alberti, K. G., Zimmet, P. \& Shaw, J. International Diabetes Federation: a consensus on type 2 diabetes prevention. Diabet. Med. 2007; 24, 451-463.

- Alexander GC, Gallagher SA, Mascola A, Moloney RM, Stafford RS. Increasing off-label use of antipsychotic medications in the United States, 1995-2008. Pharmacoepidemiol Drug Saf. 2011; 20(2): 177-184.

- Alexopoulos GS, Streim J, Carpenter D, Docherty JP. Using antipsychotic agents in older patients. J Clin Psychiatry. 2004; 65(suppl 2): 5-104.

- Atkins D, Best D, Briss PA, et al; GRADE Working Group. Grading quality of evidence and strength of recommendations. BMJ. 2004; 328(7454): 1490.

- Barlow DH, Farchione TJ, Firholme CP, Ellard KK, Boisseau CL, Allen LB, et al. Unified protocol for transdiagnostic treatment of emotional disorders. Therapist guide. New York: Oxford University Press; 2011

- Barnes, T. R. et al. A UK audit of screening for the metabolic side effects of antipsychotics in community patients. Schizophr. Bull. 2007; 33, 1397-1403.

- Bharucha AJ, Rosen J, Mulsant BH, Pollock BG. Assessment of behavioral and psychological symptoms of dementia. CNS Spectr. 2002; 7(11): 797-802.

- Brauer R, Douglas I, Smeeth L. The association between antipsychotic agents and the risk of myocardial infarction: a systematic review. Br J Clin Pharmacol 2011; 72: 871-8.

- Chien IC, Bih SH, Chou YJ, Lin CH, Lee WG, Chou P (2007): Trends in the use of psychotropic drugs in Taiwan: A populationbased national health insurance study. Psychiatr Serv. 19972004; 58: 554 -557.

- Coccurello, R. \& Moles, A. Potential mechanisms of atypical antipsychotic-induced metabolic derangement: clues for understanding obesity and novel drug design. Pharmacol. Ther. 2010; 127, 210-251

- Correll CU, Lencz T, Malhotra AK. Antipsychotic drugs and obesity. Trends Mol Med 2011; 17: 97-107. 7. 
- Correll CU, Leucht S, Kane JM. Lower risk for tardive dyskinesia associated with secondgeneration antipsychotics: a systematic review of one-year studies. Am J Psychiatry. 2004; 161(3): 414425.

- De Hert, M. et al. Cardiovascular disease and diabetes in people with severe mental illness position statement from the European Psychiatric Association (EPA), supported by the European Association for the Study of Diabetes (EASD) and the European Society of Cardiology (ESC). Eur. Psychiatry. 2009; 24, 412-424.

- De Hert M, Detraux J, van Winkel R et al. Metabolic and cardiovascular adverse effects associated with antipsychotic drugs. Nat Rev Endocrinol 2012; 8: 114-26.

- Dixon LB, Dickerson F, Bellack AS, Bennett M, Dickinson D, Goldberg RW, Lehman A, Tenhula WN, Calmes C, Pasillas RM, Peer J, Kreyenbuhl J. Schizophrenia Patient Outcomes Research Team (PORT). The 2009 schizophrenia PORT psychosocial treatment recommendations and summary statements. Schizophr Bull. 2010; 36(1): 48-70.

- Evans JD, Bond GR, Meyer PS, Kim HW, Lysaker PH, Gibson PJ, Tunis S. Cognitive and clinical predictors of success in vocational rehabilitation in schizophrenia. Schizophr Res. 2004; 70(2-3): 331-42.

- Fischer-Barnicol D, Lanquillon S, Haen E, Zofel P, Koch HJ, Dose $M$, Klein HE, Working Group 'Drugs in Psychiatry'. Typical and atypical antipsychotics - the misleading dichotomy. Results from the Working Group 'Drugs in Psychiatry' (AGATE). Neuropsychobiology. 2008; 57(1-2): 80-7.

- Fleischhacker, W.W. et al. Comorbid somatic illnesses in patients with severe mental disorders: clinical, policy, and research challenges. J. Clin. Psychiatry. 2008; 69, 514-519

- Gill, SS, Rochon, PA, Herrmann, N, Lee, PE, Sykora, K, Gunraj, N, et al. Atypical antipsychotic drugs and risk of ischaemic stroke: population based retrospective cohort study. BMJ. 2005; 330: 445-451.

- Green MF, Penn DL, Bentall R, Carpenter WT, Gaebel W, Gur RC, Kring AM, Park S, Silverstein SM, Heinssen R. Social cognition in schizophrenia: an NIMH workshop on definitions, assessment, and research opportunities. Schizophr Bull. 2008; 34(6): 121120.

- Hartemink, N., Boshuizen, H. C., Nagelkerke, N. J., Jacobs, M. A. \& van Houwelingen, H. C. Combining risk estimates from observational studies with different exposure cutpoints: a meta-analysis on body mass index and diabetes type 2. Am. J. Epidemiol. 2006; 163, 1042-1052

- Harvey PD, Green MF, Bowie C, Loebel A. The dimensions of clinical and cognitive change in schizophrenia: evidence for independence of improvements. Psychopharmacology (Berl). 2006; 187(3): 356-63.

- Hasnain M, Fredrickson SK, Vieweg WV, Pandurangi AK. Metabolic syndrome associated with schizophrenia and atypical antipsychotics. Curr. Diab. Rep. 2010; 10, 209-216.

- Haupt DW et al. Prevalence and predictors of lipid and glucose monitoring in commercially insured patients treated with second-generation antipsychotic agents. Am. J. Psychiatry. 2009; 166, 345-353.
- Hennekens CH, Hennekens AR, Hollar D, Casey DE. Schizophrenia and increased risks of cardiovascular disease. Am. Heart J. 2005; 150, 1115-1121.

- Herrmann N, Mamdani M, Lanctot KL. Atypical antipsychotics and risk of cerebrovascular accidents. Am J Psychiatry. 2004; 161: 1113-1115.

- Kales HC, Valenstein M, Kim HM, McCarthy JF, Ganoczy D, Cunningham F, et al. Mortality risk in patients with dementia treated with antipsychotics versus other psychiatric medications. Am J Psychiatry. 2007; 164: 1568-1576.

- Kane JM, Correll CU. Past and present progress in the pharmacologic treatment of schizophrenia. J Clin Psychiatry. 2010; 71: 1115- 24.

- Keefe RS, Vinogradov S, Medalia A, Silverstein SM, Bell MD, Dickinson D, Ventura J, Marder SR, Stroup TS. Report From the Working Group Conference on Multisite Trial Design for Cognitive Remediation in Schizophrenia. Schizophr Bull. 2010, Mar 1. Epub ahead of print.

- Kessing, L. V., Thomsen, A. F., Mogensen, U. B. \& Andersen, P. K. Treatment with antipsychotics and the risk of diabetes in clinical practice. Br. J. Psychiatry. 2010; 197, 266-271.

- Kleijer BC, van Marum RJ, Egberts AC et al. Risk of cerebrovascular events in elderly users of antipsychotics. J Psychopharmacol 2009; 23: 909-14.

- Lambert M, Schimmelmann BG, Naber D, Schacht A, Karow A, Wagner T, Czekalla J. Prediction of remission as a combination of symptomatic and functional remission and adequate subjective well-being in 2960 patients with schizophrenia. J Clin Psychiatry. 2006; 67(11): 1690-7.

- Lambert, T. J. \& Newcomer, J. W. Are the cardiometabolic complications of schizophrenia still neglected? Barriers to care. Med. J. Aust. 2009; 190, 39-42.

- Layton, D, Harris, S, Wilton, LV, Shakir, SA. Comparison of incidence rates of cerebrovascular accidents and transient ischemic attacks in observational cohort studies of patients prescribed risperidone, quetiapine or olanzapine in general practice in England including patients with dementia. J Psychopharmacol. 2005; 19: 473-482.

- Lehman AF, Goldberg R, Dixon LB, McNary S, Postrado L, Hackman A, McDonnell K. Improving employment outcomes for persons with severe mental illnesses. Arch Gen Psychiatry. 2002; 59(2): 165-72.

- Maayan, L. and Correll, C.U. Management of antipsychotic related weight gain. Expert Rev. Neurother. 2010; 10, 11751200

- Maayan, L. et al. Effectiveness of medications used to reduce antipsychotic-related weight gain and metabolic abnormalities: a systematic review and meta-analysis. Neuropsychopharmacology. 2010; 35,1520-1530

- Maher AR, Maglione M, Bagley S et al. Efficacy and comparative effectiveness of atypical antipsychotic medications for off-label uses in adults: a systematic review and meta-analysis. JAMA. 2011; 306: 1359-69.

- McGurk SR, Schiano D, Mueser KT, Wolfe R. Implementation of the thinking skills for work program in a psychosocial clubhouse. Psychiatr Rehabil J. 2010; 33(3): 190-9. 
- Mitchell, A. J., Delaffon, V., Vancampfort, D., Correll, C. U. \& De Hert, M. Guideline concordant monitoring of metabolic risk in people treated with antipsychotic medication: systematic review and meta-analysis of screening practices. Psychol. Med. 2012; 42(1): 125-47

- Mittal V, Kurup L, Williamson D, Muralee S, Tampi RR. Risk of cerebrovascular adverse events and death in elderly patients with dementia when treated with antipsychotic medications: A literature review of evidence. Am J Alzheimers Dis Other Demen. 2011; 26: $10-28$.

- Morrato, E. H. et al. Metabolic screening in children receiving antipsychotic drug treatment. Arch. Pediatr. Adolesc Med. 2010; 164, 344-351.

- Morrato, E. H. et al. Metabolic testing rates in 3 state Medicaid programs after FDA warnings and ADA/APA recommendations for second-generation antipsychotic drugs. Arch. Gen. Psychiatry. 2010; 67, 17-24.

- Naber D, Karow A, Lambert M. Subjective well-being under the neuroleptic treatment and its relevance for compliance. Acta Psychiatr Scand Suppl. 2005; (427): 29-34.

- Nasrallah HA, White T, Nasrallah AT. Lower mortality in geriatric patients receiving risperidone and olanzapine versus haloperidol preliminary analysis of retrospective data. Am J Geriatr Psychaitry. 2004; 12(4): 437-439.

- Olfson M, Blanco C, Liu SM, et al. National trends in the officebased treatment of children, adolescents, and adults with antipsychotics. Arch Gen Psychiatry. 2012; 69: 1247-56.

- Parsons, B. et al. Weight effects associated with antipsychotics: a comprehensive database analysis. Schizophr. Res. 2009; 110, 103-110.

- Paulose-Ram R, Safran MA, Jonas BS, Gu Q, Orwig D. Trends in psychotropic medication use among U.S. adults. Pharmacoepidemiol Drug Saf. 2007; 16: 560 -570.

- Qin, L., Knol, M. J., Corpeleijn, E. \& Stolk, R. P. Does physical activity modify the risk of obesity for type 2 diabetes: a review of epidemiological data. Eur. J. Epidemiol. 2010; 25, 5-12.

- Schneider LS, Pollock VE, Lyness SA. A metaanalysis of controlled trials of neuroleptic treatment in dementia. J Am Geriatr Soc. 1990; 38(5): 553-563.

- Schramm E, Hautzinger M, Zobel I, Kriston L, Berger M, Härter M. Comparative efficacy of the cognitive behavioral analysis system of psychotherapy versus supportive psychotherapy for early onset chronic depression: design and rationale of a multisite randomized controlled trial. BMC Psychiatry. 2011; 11: 134.

- Sheehan DV, McElroy SL, Harnett-Sheehan K, et al. Randomized, placebo-controlled trial of risperidone for acute treatment of bipolar anxiety. J Affect Disord. 2009; 115(3): 376-385.

- Simon, V., van Winkel, R. \& De Hert, M. Are weight gain and metabolic side effects of atypical antipsychotics dose dependent? A literature review. J. Clin. Psychiatry. 2009; 70, 1041-1050.

- Spielmans GI, Berman MI, Linardatos E et al. Adjunctive atypical antipsychotic treatment for major depressive disorder: a metaanalysis of depression, quality of life, and safety outcomes. PLoS Med 2013; 10: 1-24.
- Wang, PS, Schneeweiss S, Avorn, J, Fischer, MA, Mogun, H, Solomon, $\mathrm{DH}$, et al. Risk of death in elderly users of conventional vs atypical antipsychotic medications. N Engl J Med. 2005; 353: 2335-2341.

- Wheeler, A. J. et al. Cardiovascular risk assessment and management in mental health clients: whose role is it anyway? Community Ment. Health J. 2010; 46, 531-539.

- Wooltorton E. Risperidone (Risperdal): Increased rate of cerebrovascular events in dementia trials. CMAJ. 2002; 167: $1269-1270$.

- Wu CS, Wang SC, Gau SS et al. Association of stroke with the receptor-binding profiles of antipsychotics - a case-crossover study. Biol Psychiatry. 2013; 73: 414-21.

\section{Comment on this article:}

\section{9 (3) in $8+9$}

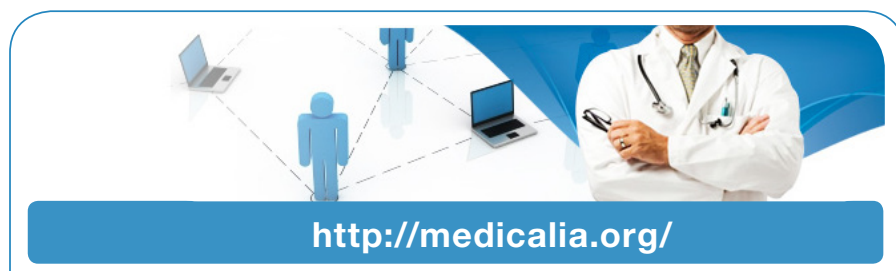

Where Doctors exchange clinical experiences, review their cases and share clinical knowledge. You can also access lots of medical publications for free. Join Now!

\section{Publish with iMedPub}

\section{http://www.imed.pub}

International Archives of Medicine is an open access journal publishing articles encompassing all aspects of medical science and clinical practice. IAM is considered a megajournal with independent sections on all areas of medicine. IAM is a really international journal with authors and board members from all around the world. The journal is widely indexed and classified Q1 in category Medicine. 